\title{
Application of Computer 3D Animation in Taijiquan Teaching Based on the Data Analysis
}

\author{
Guanqiang Yang ${ }^{1}$, Jinli $\mathrm{Ma}^{2}$ \\ ${ }^{1}$ Institute of Physical Education, Shihezi University, Shihezi, China \\ y_ang_guanqiang@126.com \\ ${ }^{2}$ Personnel division, Shihezi University, Shihezi, China
}

Keywords: three animation techniques; questionnaire; bones simulation; synthesis model

\begin{abstract}
. with the development of the technology, the techniques of computer and internet are becoming mature. People can break the restriction of time and space to acquire knowledge, which drives the change of the traditional teaching methods. Now the new model which is the combination of computers and internet will grow to a new trend. The teaching difficulties of Taijiquan are that the teachers can't teach the basic essentials completely by words because we can not see the bones movements when teaching. Therefore, both teaching and learning are difficult, which influences the teaching quality. In this article we put 3D animation techniques into Taijiquan Teaching, so that the beginners can see the bones movements clearly. It also demonstrates Taijiquan from different aspects to have it easily mastered.
\end{abstract}

\section{Background}

Taijiquan, the quintessence of China, is one kind of traditional Wushu Sport. It not only can secure oneself, but also can keep the body healthy because of the characteristics of performance and respiratory regulation. But when teaching Taijiquan, because of the abstractive spinal movement, teaching Taijiquan has been a problem for hundreds of years. For example, the movement of lower reaches, lumbar, Jiaji, and shoulder blade can not be expressed clearly. So the essence gathered by ancestors can't be described directly to the students. Only with IQ 120 can the students understand it. Therefore, many students have to simply the spinal movement and pay more attention to movements of hands and feet, and some Taijiquan teachers are blamed that they are conservative. Now the computer 3D animation technique brings the Taijiquan teaching a ray of hope. This skill can imitate the movement of the bones, showing the movement of each bone to everyone. 3D animation teaching method is the fruit of the combination of the traditional Wushu Culture and modern computer techniques. From now on, most students can reap the benefits from the 3D teaching method. In this article, by discussing the feasibility and value of applying 3D animation teaching method in Taijiquan teaching, we can make contribution to the teaching of Taijiquan.

\section{Research Approaches}

\section{A. Handing out the questionnaires}

First, we should hand out the questionnaires to evaluate whether 3D Taijiquan Animation can satisfy both the teachers and the students. The content of the questionnaire covers basic data structures, learning needs, the extent of solving problems, and ideas and suggestions. In order to analyze easily, we provide the answers as totally agree ( 2 points), agree (1 point), no suggestions ( 0 point), disagree (-1 point) and totally disagree (-2 points).

B. Sorting out the data

130 questionnaires have been handed out and 130 have been collected. 70.4\% haven't learned Taijiquan. 29.6\% have learned it. In this article we analyze the data from the questionnaires. 


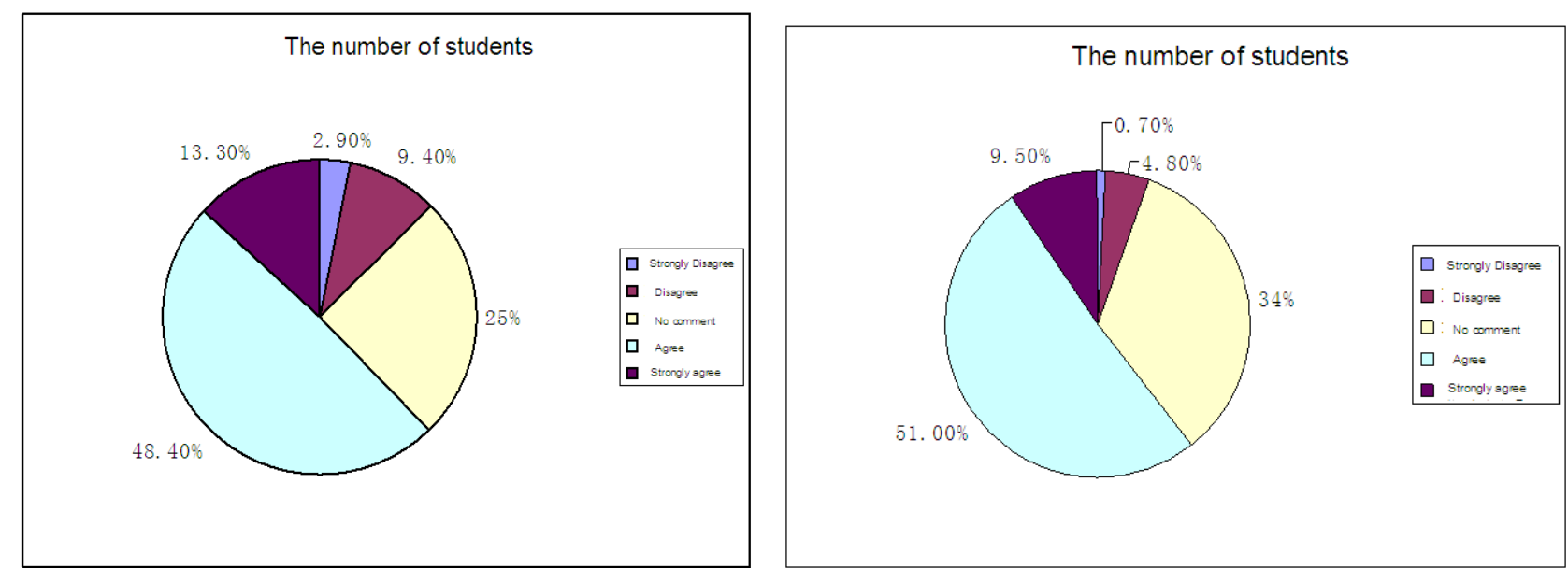

Figure 1. Questionnaire from the Students Who Have Learnt TaijquanFigure2. Questionnaire form the Students Who Haven't Learnt Taijiquan TABLE I. SCORE TABLE OF QUESTIONNAIRE FORM THE STUDENTS WHO HAVE LEARNT TAIJIQUAN

\begin{tabular}{|c|l|}
\hline Average & 14.6 \\
\hline Standard Error & 2.36 \\
\hline Mediant & 17 \\
\hline Mode & 0 \\
\hline Standard Deviation & $14.1=$ \\
\hline Variance & 199.6 \\
\hline Range of Values & 69 \\
\hline Minimum Number & -23 \\
\hline Maximum Number & 45 \\
\hline Sum & 539 \\
\hline Reliability Value(95.0\%) & 4.7 \\
\hline
\end{tabular}

TABLE II. SCORE TABLE OF QUESTIONNAIRE FORM THE STUDENTS WHO HAVEN'T LEARNT TAIJIQUAN

\section{Analyzing the data}

\begin{tabular}{|c|l|}
\hline Average & 15.4 \\
\hline Standard Error & 1.1 \\
\hline Mediant & 16 \\
\hline Mode & 14 \\
\hline Standard Deviation & 10.3 \\
\hline Variance & 106.0 \\
\hline Range of Values & 64 \\
\hline Minimum Number & -15 \\
\hline Maximum Number & 44 \\
\hline Sum & 1362 \\
\hline Reliability Value (95.0\%) & 2.2 \\
\hline
\end{tabular}

Use the data in Table 3 to implement the hypothesis test. Because $P(Z<z)=0.74$, which means that it is not within the rejection region $Z>1.96$, the suppose can't be accepted. According to the above suppose, there is no significant difference between the students who have and haven't learnt Taijiquan.

\begin{tabular}{|c|c|c|}
\hline & Students Who Learnt Taijiquan & $\begin{array}{c}\text { Students Who Haven't Learnt } \\
\text { Taijiquan }\end{array}$ \\
\hline Average & 14.6 & 15.5 \\
\hline The Known Variation Value & 199.6 & 105.9 \\
\hline Number of Observed Value & 36 & 90 \\
\hline Supposed Average & 0.0 & \\
\hline $\mathbf{Z}$ & -0.33 & \\
\hline$P(Z \leq z)$ Unilateral & 0.38 & \\
\hline Threshold Value: Unilateral & 1.6 & \\
\hline$P(Z \leq z)$ Bilateral & 0.74 & \\
\hline Threshold Value: Bilateral & 1.96 & \\
\hline
\end{tabular}




\section{The Design of 3D Animation}

\section{The Research Flow Chart}

After the argumentation, we design a flow chart as below,

\section{Method of Design}

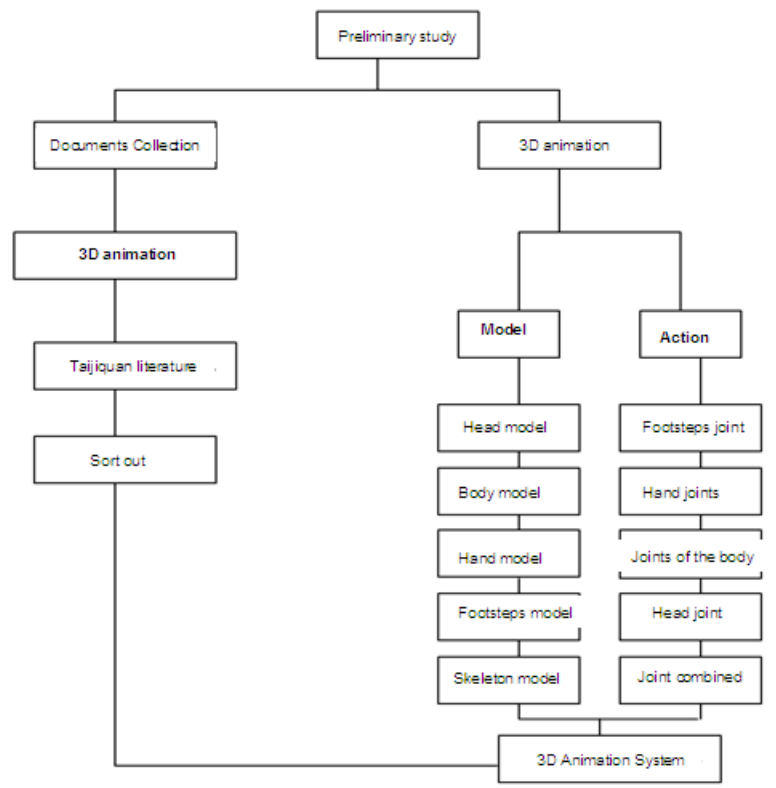

Figure 2. The Research Flow Chart

(1)Collecting information and designing the image

(2)Making Movement Model

(3) Setting the bones and skin system and the preparation for the animation

(4)Adjustment of the animation

(5)Rendering

(6) Composition
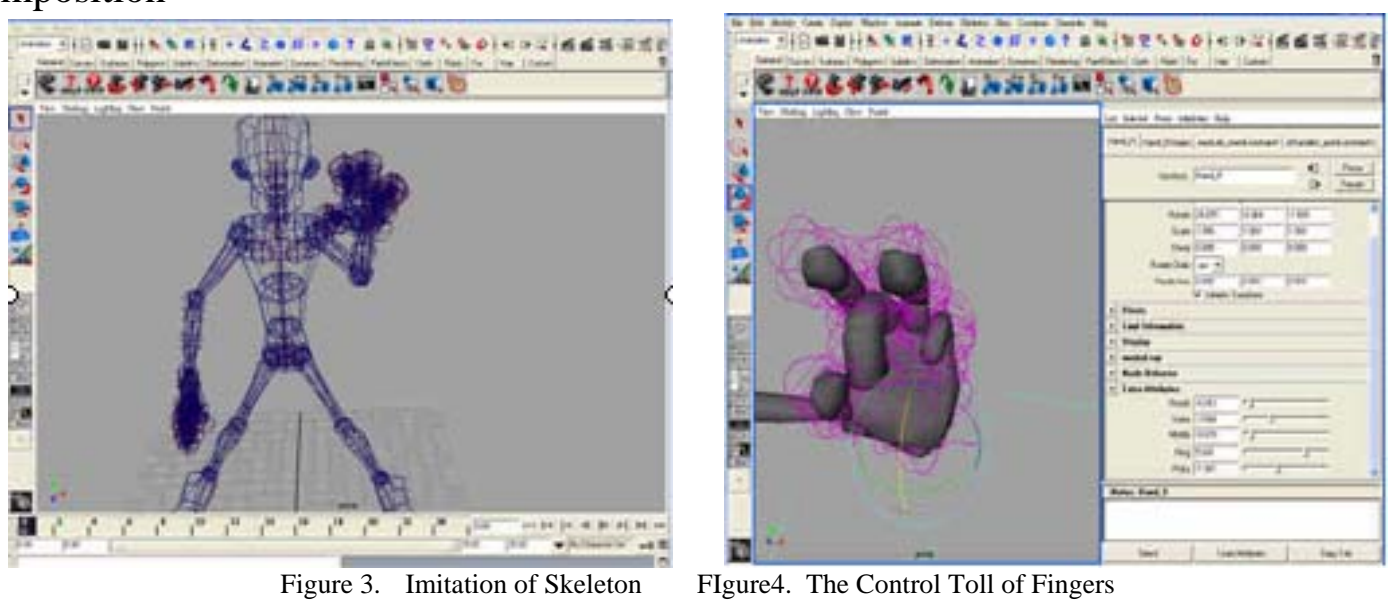

\section{The Advantage of Computer 3D Animation Technique in Teaching Taijiquan}

Arousing the students' interests to study and cultivating the self-study ability

The Computer 3D animation technique can show the information such as animation, image, music, words vividly to the students in Teaching Taijiquan. The students can feel the movements of Taijiquan, so that they can observe the demonstration in all domains and have deeper impression. The students will have more interests in learning. The students who don't understand in class can learn after class by seeing 3D animation. So the computer 3D animation technique can arouse the students study interests, cultivate their self study ability and lay the foundation for the sport consciousness.

Improving the teaching quality in class

The assisted instruction of computer 3D animation technique can demonstrate the movement and leave deep impression of the contents, steps and methods, which can help the teachers to explain the 
difficulties and key points. This also can provide standard movements for both the teachers and the students. The teaching quality may be improved greatly after the repeated practice of the students.

Reducing the burden from the teachers

The knowledge can be delivered to students by using the modern teaching methods, such as illustrations, texts, sound and pictures. By these means, the students can have a deeper understanding to the abstractive process and the tasks of the teachers can be reduced correspondingly. Meanwhile, according to their own situation, the students may choose different contents and studying stages with flexibility. In this way, the self study ability can be easily promoted.

Providing feedback promptly and correcting the mistakes

The movements of Taijiquan are complicated and there are too many contents for the teachers to teach. It is difficult for the teachers to care the whole learning procedure of the students. The computer 3D animation technique can help the students to see the movements repeatedly and have deeper impression.

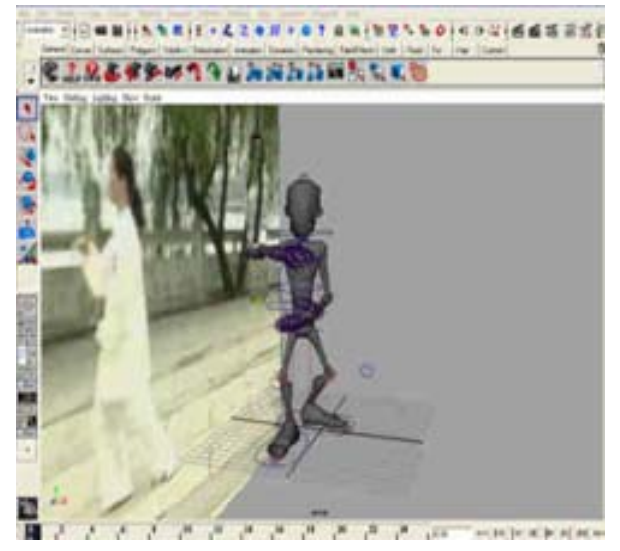

Figure5. Imitation of Movements

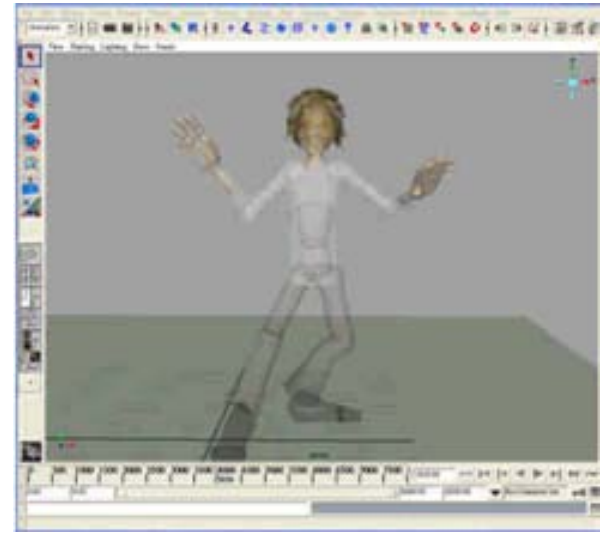

Figure6. The Compounded Model

\section{Conclusion}

With the development of the technology, the techniques of computer and internet are becoming mature. People can break the restriction of time and space to acquire knowledge, which drives the change of the traditional teaching methods. Now the new model which is the combination of computers and internet will grow to a new trend. The teaching difficulties of Taijiquan are that the teachers can't teach the basic essentials completely by words because we can not see the bones movements when teaching. Therefore, both teaching and learning are difficult, which influences the teaching quality. In this article we put 3D animation techniques into Taijiquan Teaching, so that the beginners can see the bones movements clearly. It also demonstrates Taijiquan from different aspects to have it easily mastered. This technique brings the creative significance to the present Taijiquan Teaching.

\section{References}

[1] Zhang Xiaodong, Preliminary Study on the Computer Assistance to PE Theory Teaching [J], Capital Institute of Physical Education Journal, 2003, 9(3)

[2] Zhang Jianping, The Integration of Computer Technology and College PE Teaching [J], Beijing Sport University Journal, 2002,9(5).

[3] Zhang Yuanyuan, Research on 3D Animation Teaching in Vocational College [J], Computer Knowledge and Technology, 2010,(12).

[4] Li Zhonghua, Implement Scientific Concept of Development and Improve the Research Work of New Upgraded Vocational Colleges [J], Changsha Communications Vocational and Technical College Journal, 2006,(03).

[5] Xu Jiangtao, Li Yajuan \& Wang Jing, Computer Basic Teaching in Vocational Colleges [J], Ankang Teachers School Journal, 2006, (04).

[6] Huang Keli, Analysis of Computer Network Teaching in Vocational Colleges [J], Shanxi Education (Theory Version), 2006, (Z2) 